\title{
Methane reforming over Ni-based pyrochlore catalyst: deactivation studies for different reactions
}

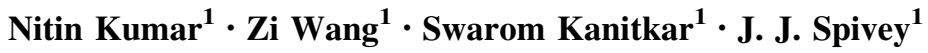

Received: 22 January 2016/Accepted: 27 June 2016/Published online: 21 July 2016

(c) The Author(s) 2016. This article is published with open access at Springerlink.com

\begin{abstract}
A 1 wt $\%$ Ni-based $\mathrm{La}_{2} \mathrm{Zr}_{2} \mathrm{O}_{7}$ pyrochlore catalyst was synthesized using the modified Pechini method. The catalyst was characterized by $\mathrm{H}_{2}$-TPR, and pre- and postreaction XRD, and tested for its methane-reforming activity under three different reaction conditions: (a) dryreforming $\left(\mathrm{CH}_{4}+\mathrm{CO}_{2}\right)$, (b) oxy- $\mathrm{CO}_{2}$ reforming $\left(\mathrm{CH}_{4}+\mathrm{CO}_{2}+\mathrm{O}_{2}\right)$, and (c) bi-reforming $\left(\mathrm{CH}_{4}+\right.$ $\mathrm{CO}_{2}+\mathrm{H}_{2} \mathrm{O}$ ). The TPR results show that $\mathrm{NiO}$ in the fresh, calcined catalyst is completely reversible to $\mathrm{Ni}^{0}$. The XRD results show that the crystalline pyrochlore structure is stable under all three reaction conditions. Under dry-reforming conditions, the catalyst deactivated rapidly. In oxy-reforming, the catalyst activity also decreased, but far less rapidly than under dry-reforming conditions. However, under bi-reforming conditions, no deactivation was observed at comparable times-on-stream. TPO of the spent catalysts showed greatest carbon deposition for the dryreforming, a significant portion of which was graphitic and difficult to remove. For oxy-reforming, there was much less carbon deposition as compared to the dry-reforming, and a major part of which was the amorphous, atomic carbon, which is relatively easy to remove. Unlike under bi-reforming, no significant carbon deposition was observed at the conditions tested here. This indicates that the presence of steam resists carbon deposition compared to dry-reforming or oxy-reforming.
\end{abstract}

\footnotetext{
J. J. Spivey

jjspivey@1su.edu

1 Louisiana State University, Baton Rouge, LA 70803, USA
}

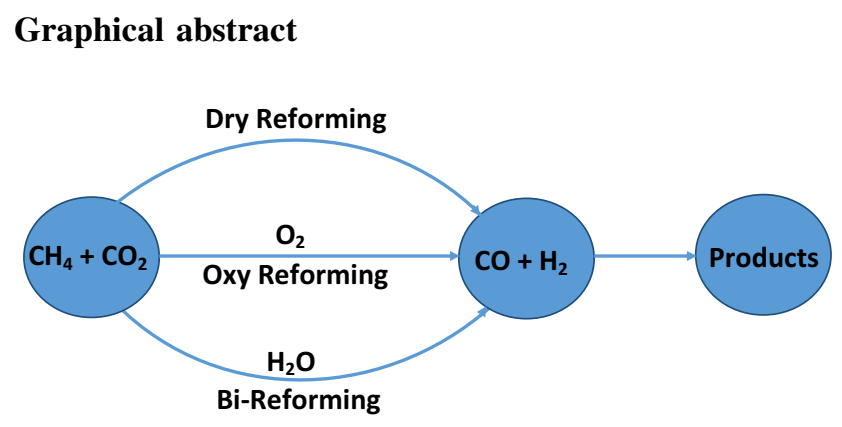

Keywords Reforming · Dry-reforming · Bi-reforming . Oxy-reforming $\cdot$ Pyrochlore $\cdot$ Syngas $\cdot$ Methane activation

\section{Introduction}

The production of synthesis gas from methane and $\mathrm{CO}_{2}$ is receiving significant research interest worldwide [1, 2]. Methane and $\mathrm{CO}_{2}$ are the main components of some natural gas resources, including coalbed gases, and are potential large sources of energy. The production of these gases is predicted to increase in the near future [3]. The conversion of methane and $\mathrm{CO}_{2}$ to syngas requires demanding conditions, e.g., temperatures above $\sim 800^{\circ} \mathrm{C}$, making it even more important to efficiently convert these gases into useful products using stable, active catalysts.

Many different reactions are studied that utilize both $\mathrm{CH}_{4}$ and $\mathrm{CO}_{2}$, but the most viable option is the catalytic conversion of these gases to produce syngas, a mixture of $\mathrm{CO}$ and $\mathrm{H}_{2}$ [4]. Syngas can be used to produce a range of high-value chemicals, such as methanol, higher oxygenates, and Fischer-Tropsch products [5-8]. Some of the 
options available for direct conversion of these gases to produce syngas are given below:

Dry-reforming: $\mathrm{CH}_{4}+\mathrm{CO}_{2} \rightleftharpoons 2 \mathrm{CO}+2 \mathrm{H}_{2}$

$\Delta H_{298 \mathrm{~K}}=+247 \mathrm{~kJ} / \mathrm{mol}, \Delta G_{298 \mathrm{~K}}=+170 \mathrm{~kJ} / \mathrm{mol}$

Oxy- $\mathrm{CO}_{2}$ reforming: $3 \mathrm{CH}_{4}+\mathrm{CO}_{2}+\mathrm{O}_{2} \rightleftharpoons 4 \mathrm{CO}+6 \mathrm{H}_{2}$

$\Delta H_{298 \mathrm{~K}}=+58 \mathrm{~kJ} / \mathrm{mol}, \Delta G_{298 \mathrm{~K}}=-1 \mathrm{~kJ} / \mathrm{mol}$

Bi-reforming: $3 \mathrm{CH}_{4}+\mathrm{CO}_{2}+2 \mathrm{H}_{2} \mathrm{O} \rightleftharpoons 4 \mathrm{CO}+8 \mathrm{H}_{2}$

$\Delta H_{298 \mathrm{~K}}=+220 \mathrm{~kJ} / \mathrm{mol}, \Delta G_{298 \mathrm{~K}}=+151 \mathrm{~kJ} / \mathrm{mol}$

Dry-reforming produces a syngas with $1 / 1 \mathrm{H}_{2} / \mathrm{CO}$ ratio, and therefore, extra $\mathrm{H}_{2}$ must be added for the downstream Fischer-Tropsch or methanol synthesis. One of the challenges associated with dry-reforming is that of the carbon deposition, which typically results in the severe, rapid deactivation [9]. Oxy- $\mathrm{CO}_{2}$ reforming, on the other hand, is much less endothermic compared to the dryreforming, which could result in significant energy savings. However, severe temperature gradients within the catalyst bed can deactivate the catalyst, especially for the scaled-up systems. The syngas produced in oxy-reforming also falls short of the desired $2 / 1 \mathrm{H}_{2} / \mathrm{CO}$ ratio. The bi-reforming reaction, although highly endothermic, results in the desired $2 / 1 \mathrm{H}_{2} / \mathrm{CO}$ ratio, and the process can be directly coupled with the downstream $\mathrm{F}-\mathrm{T}$ or methanol synthesis processes.

All technologies to reform $\mathrm{CH}_{4}$ and $\mathrm{CO}_{2}$ directly to syngas face with several challenges. These challenges arise mainly due to the highly endothermic nature of the reaction itself, which requires high temperatures $(\sim 800$ to $1000{ }^{\circ} \mathrm{C}$ ) to reach high equilibrium conversions. At these conditions, many catalysts are not thermally stable as a result of sintering or collapse of the crystal structure. Another major problem is due to carbon deposition, which results in deactivation. Therefore, the reforming catalyst should meet these important criteria: (a) thermal stability of the support, (b) resistance to sintering of the active metal, (c) resistance to carbon deposition, and (d) high activity with time-on-stream to reach equilibrium conversions.

One approach is to add active metals to a thermally stable crystalline oxide, such as a pyrochlore, as has been shown to be promising for dry-reforming [9-12]. Pyrochlores are highly crystalline defect fluorite oxide with the general formula of $\mathrm{A}_{2} \mathrm{~B}_{2} \mathrm{O}_{7}$, where $\mathrm{A}$ is a lanthanide series element, and $\mathrm{B}$ is a transition metal, and the ionic ratio of $r_{\mathrm{A}} / r_{\mathrm{B}}$ is 1.4-1.6. They have proven high temperature stability in various applications, such as gas turbine thermal barrier coatings [13], but have only recently been investigated as catalysts. The pyrochlore structure, if properly synthesized, can incorporate active metals, such as $\mathrm{Ni}$, at low loadings. This provides a strong interaction between the active metal and the support, which can significantly improve the coke resistance of the catalyst [14]. The first use of pyrochlore as catalysts was by Ashcroft et al. [15], where they tested the structure with several active metals. However, their pyrochlore structure collapsed at dry-reforming conditions at $660{ }^{\circ} \mathrm{C}$.

In the present work, a Ni-based pyrochlore having $\mathrm{La}_{2} \mathrm{Zr}_{2} \mathrm{O}_{7}$ was synthesized by modified Pechini method $[16,17]$ and characterized using TPR/TPO and XRD. The catalyst was tested under three reforming reaction conditions at a reference temperature of $750{ }^{\circ} \mathrm{C}$ : (a) dry-reforming (reaction 1), (b) oxy-reforming (reaction 2), and (c) bi-reforming (reaction 3). The spent catalyst from each reaction was characterized using temperature program oxidation (to investigate carbon deposition) and XRD (to investigate any structural changes).

\section{Experimental}

\section{Catalyst preparation}

The $1 \%$ LNZ pyrochlore catalyst was prepared using a modified Pechini method. The preparation method produces highly uniform crystallites and is explained in detail elsewhere [12, 16-21]. The precursors used for $\mathrm{La}, \mathrm{Ni}$, and $\mathrm{Zr}$ were lanthanum nitrate $\left[\mathrm{La}\left(\mathrm{NO}_{3}\right)_{3} \cdot 6 \mathrm{H}_{2} \mathrm{O}\right]$, nickel nitrate $\left[\mathrm{Ni}\left(\mathrm{NO}_{3}\right)_{2} \cdot 6 \mathrm{H}_{2} \mathrm{O}\right]$, and zirconium nitrate $\left[\mathrm{ZrO}\left(\mathrm{NO}_{3}\right)_{2}\right.$ $\cdot n \mathrm{H}_{2} \mathrm{O}$ ], respectively. The nitrate salts were separately dissolved in deionized water and then mixed with a citric acid (CA) solution in a molar ratio of CA:metal $=1.2: 1$. The solution was continuously stirred and heated to $75^{\circ} \mathrm{C}$ to ensure complete metal complexation. At $75{ }^{\circ} \mathrm{C}$, a $1: 1$ molar ratio of ethylene glycol (EG) to CA was added to the solution. The solution was kept stirred on the hot plate until most of the water had evaporated and a transparent, viscous gel was obtained. After this the stirring was stopped and the gel was left on the hot plate to promote the polyesterification reaction between EG and CA to form an organic polymeric network. The nitrate precursors started to decompose at this condition, which was evident from the large plumes of $\mathrm{NO}_{\mathrm{x}}$ and bubbling in the gel. The resulting foam-like mixture was placed in an oven at $110{ }^{\circ} \mathrm{C}$ to dry overnight. The mixture was then calcined at $1000{ }^{\circ} \mathrm{C}$ for $8 \mathrm{~h}$ to oxidize the organic precursors and form the pyrochlore catalyst.

\section{Temperature-programmed reduction (TPR)}

Temperature-programmed reduction (TPR) profiles of the calcined catalyst were recorded using an Altamira AMI 
200 unit equipped with a thermal conductivity detector (TCD) [21]. $50 \mathrm{mg}$ of catalyst sample was first oxidized in a fixed-bed micro-reactor system under flowing $5 \% \mathrm{O}_{2} / \mathrm{He}$ at $950{ }^{\circ} \mathrm{C}$. It was then cooled to $25^{\circ} \mathrm{C}$ under helium flow. TPR was performed using a $10 \% \mathrm{H}_{2} / \mathrm{Ar}$ mixture at a flow rate of $50 \mathrm{~cm}^{3} / \mathrm{min}$, while the temperature was linearly ramped from 25 to $950{ }^{\circ} \mathrm{C}$ at $10{ }^{\circ} \mathrm{C} / \mathrm{min}$. The catalyst was then cooled to $25^{\circ} \mathrm{C}$ under helium flow and, then, again oxidized under $5 \% \mathrm{O}_{2} / \mathrm{He}$ at $950{ }^{\circ} \mathrm{C}$. The catalyst was again cooled back to $25^{\circ} \mathrm{C}$ under helium flow. A second TPR was carried out under the same conditions as that of the first TPR mentioned above.

\section{X-ray diffraction}

X-ray diffraction (XRD) experiments were carried out using Empyrean X-ray diffractometer (PANalytical) using $\mathrm{Cu} K_{\alpha}$ radiation $(\lambda=1.5406 \AA)$. The scan angle was varied from 0 to $90^{\circ}$ with a step size of $0.017^{\circ}$. Data analysis was done using the software X'Pert HighScore Plus (v3.0).

\section{Equilibrium calculations}

Thermodynamic equilibrium calculations were carried out using HSC Chemistry 8.0 (Outotec, Finland), which uses Gibbs free energy minimization for all the components at a given condition. Molar ratios of the feeds were taken to be the same as their stoichiometric ratios corresponding to each reaction, and calculations were carried out for all the three reaction systems: dry-reforming, oxy-reforming, and bi-reforming. Products allowed to form in the simulation were carbon, $\mathrm{CO}$, and $\mathrm{H}_{2}$. Equilibrium calculations were carried out at $1 \mathrm{~atm}$ pressure, and the amount of carbon formed for all three reaction systems at different temperatures was calculated. The amount of carbon was normalized with respect to the total carbon entering in each of the reactions so as to compare them on the same basis.

\section{Catalyst activity test}

Catalytic activity tests were carried out in a $1 / 4^{\prime \prime}$ size fixedbed reactor made of quartz, which can withstand up to $1200{ }^{\circ} \mathrm{C}$ under $1 \mathrm{~atm}$ [21]. The experiments were carried out in an AMI 200 unit (Altamira Instruments, Pittsburgh, $\mathrm{PA})$. The reactor is equipped with a thermocouple that is inserted directly into the catalyst bed to measure the actual temperature of the catalyst. Both ends of the catalyst bed were plugged with quartz wool to avoid entrainment of any catalyst particles with the gas stream. Before the reaction, the catalyst was pretreated with $10 \% \mathrm{O}_{2} / \mathrm{He}$ flow at a temperature of $800{ }^{\circ} \mathrm{C}$ followed by cooling down to room temperature under pure helium. The catalyst was then reduced under $10 \% \mathrm{H}_{2} / \mathrm{He}$ flow at $800{ }^{\circ} \mathrm{C}$. After the
Table 1 Mole\% of feeds used for various reactions on a helium-free basis

\begin{tabular}{lllll}
\hline Reaction & $\begin{array}{l}\mathrm{CO}_{2} \\
(\mathrm{~mol} \%)\end{array}$ & $\begin{array}{l}\mathrm{CH}_{4} \\
(\mathrm{~mol} \%)\end{array}$ & $\begin{array}{l}\mathrm{O}_{2} \\
(\mathrm{~mol} \%)\end{array}$ & $\begin{array}{l}\mathrm{H}_{2} \mathrm{O} \\
(\mathrm{mol} \%)\end{array}$ \\
\hline Dry-reforming & 50 & 50 & - & - \\
Oxy-reforming & 20 & 60 & 20 & - \\
Bi-reforming & 16 & 51 & - & 33 \\
\hline
\end{tabular}

reduction, the catalyst was cooled to the reaction temperature under helium flow.

The gases used for the reactions were $10 \% \mathrm{CO}_{2} / \mathrm{He}$, $10 \% \mathrm{CH}_{4} / \mathrm{He}$, and $10 \% \mathrm{O}_{2} / \mathrm{He}$. All the experiments were carried out at $1 \mathrm{~atm}$ pressure and space velocities in the range of 96,000-100,000 $\mathrm{scc} \mathrm{h}^{-1} \mathrm{~g} \mathrm{cat}^{-1}$. The molar ratios of various gases used for different reactions on a helium free basis are shown in Table 1. The experimental molar ratios were kept close to the stoichiometric ratios corresponding to different reactions.

For the bi-reforming reaction, water was fed to the reactor at a controlled rate using a HPLC pump [21]. The water flows through a vaporizer where steam is formed, which is later mixed with other gases before flowing through the catalyst bed. All the inlet and outlet lines were heat-traced to $200{ }^{\circ} \mathrm{C}$ to avoid condensation of steam. Outlet gases were analyzed using an inline quadrupole mass spectrometer.

A temperature program oxidation (TPO) was carried out on the spent catalyst after each reaction. For TPO, the catalyst was heated from room temperature to $950{ }^{\circ} \mathrm{C}$ under $10 \% \mathrm{O}_{2} / \mathrm{He}$ mixture at a ramp rate of $10^{\circ} \mathrm{C} / \mathrm{min}$, and $\mathrm{CO}_{2}$ signal (mass 44) was recorded in a mass spectrometer.

\section{Results and discussion}

\section{Temperature-programmed reduction}

The TPR results are shown in Fig. 1 [21]. The two curves represent two consecutive TPRs with an intermittent oxidation step. These two consecutive TPRs were carried out to investigate whether the catalyst retains its structure in the second TPR after the high temperature treatment in the first TPR. Figure 1 shows that these two successive TPR profiles are fully reproducible, indicating that the reduction of $\mathrm{NiO}$ and oxidation of metallic $\mathrm{Ni}$ are completely reversible. There is no detectable change in the structure of the catalyst or any sintering of the metal as a result of the $950{ }^{\circ} \mathrm{C}$ TPR/TPO.

Figure 1 also shows the reduction of nickel oxide under four different peaks. The peak at $305{ }^{\circ} \mathrm{C}$ can be attributed to the reduction of bulk $\mathrm{NiO}[22,23]$. The peaks at $352{ }^{\circ} \mathrm{C}$ 


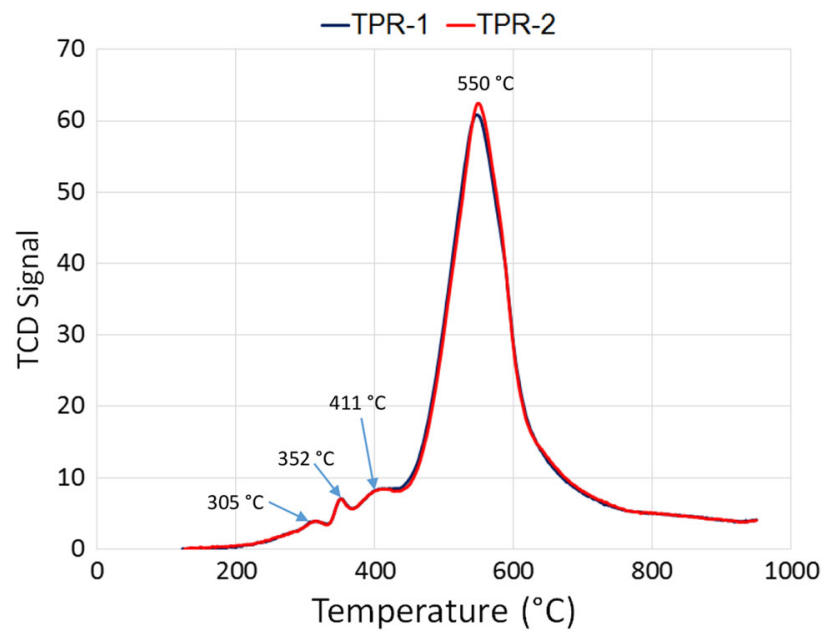

Fig. 1 Temperature program reduction results for $1 \% \mathrm{LNZ}$ catalyst [21]. The two curves represent two consecutive TPRs with an oxidation step in-between

and $411{ }^{\circ} \mathrm{C}$ can be assigned due to the sequential reduction of $\mathrm{Ni}^{3+}$ to $\mathrm{Ni}^{2+}$ and $\mathrm{Ni}^{2+}$ to $\mathrm{Ni}^{0}$, respectively [24]. Finally, most of the nickel in the catalyst is reduced under the peak at $550{ }^{\circ} \mathrm{C}$, which can be attributed to the reduction of highly dispersed $\mathrm{NiO}$ species interacting strongly with the support [25]. This indicates that most of the $\mathrm{Ni}$ in the catalyst is present in a highly dispersed form, strongly interacting with the pyrochlore support.

\section{X-ray diffraction (XRD)}

The XRD results for fresh $1 \% \mathrm{LNZ}$ and spent catalysts from the three reactions are shown in Fig. 2. Figure 2a shows the XRD patterns for fresh calcined catalyst. Figure $2 b-d$ shows the XRD patterns for spent catalysts obtained after dry-reforming, oxy-reforming, and bi-reforming reactions, respectively.

Figure 2 shows that there is no change in the peak ratios or positions for the fresh and spent catalysts from any of the three reactions, which indicates that the crystalline structure of the catalyst does not change under any of the reforming conditions. All the peaks seen in Fig. 2 correspond to that of the $\mathrm{La}_{2} \mathrm{Zr}_{2} \mathrm{O}_{7}$ phase, and no peaks corresponding to $\mathrm{NiO}$ or metallic Ni phases are observed. This is due to low metal loading and high dispersion of $\mathrm{Ni}$ in the catalyst. These results also support the argument that the pyrochlore structure is unaffected as a result of reforming at high temperatures under different feed conditions. Pyrochlore catalysts containing rare earth metals have been used by Ashcroft et al. [15] to study dry-reforming, but their structure was not stable and they observed a breakdown of the pyrochlore structure during the dry-reforming at $660{ }^{\circ} \mathrm{C}$. In our case, on the other hand, the XRD patterns for spent catalysts after dry-, oxy-, and bi-reforming

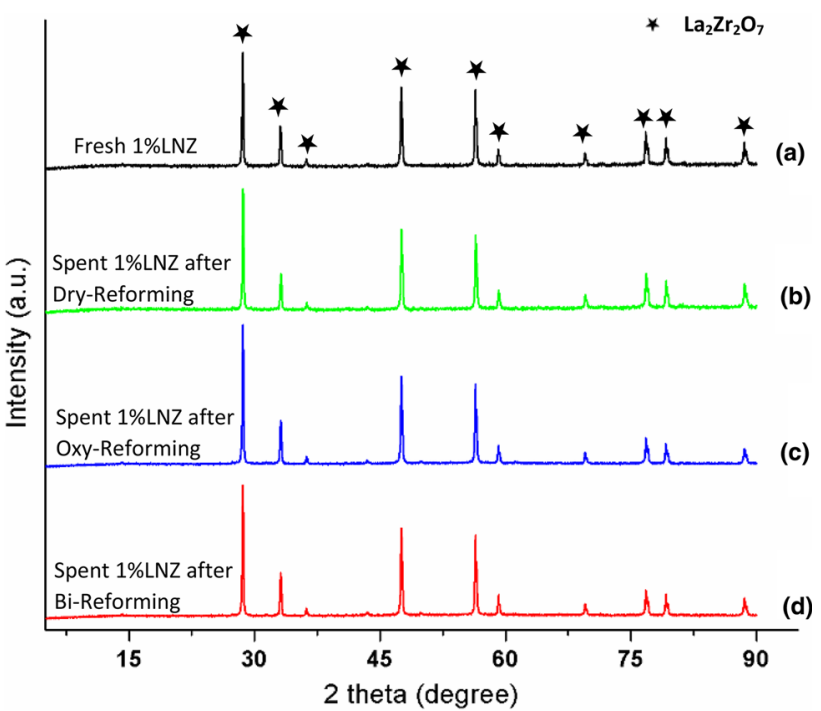

Fig. 2 XRD patterns for $1 \% \mathrm{LNZ}$ catalyst. a Fresh calcined $1 \%$ LNZ, b $1 \%$ LNZ after dry-reforming reaction, c $1 \%$ LNZ after oxyreforming reaction, and $\mathbf{d} 1 \% \mathrm{LNZ}$ after bi-reforming reaction

\section{Equilibrium Carbon Deposition}

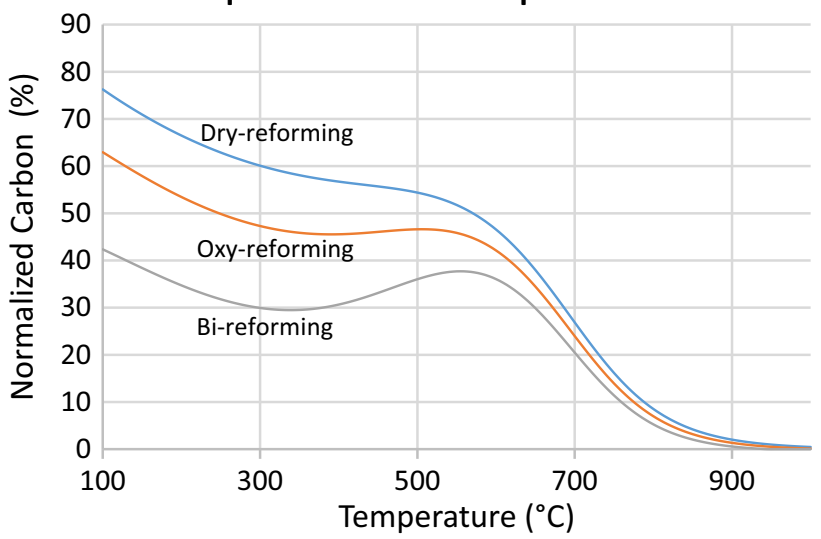

Fig. 3 Equilibrium carbon deposition for the three reactions calculated at atmospheric pressure and different temperatures using HSC Chemistry. The molar ratios of feeds were taken corresponding to the stoichiometry of the three reforming reactions

conditions were not changed when compared to that of the fresh catalyst, indicating high thermal resistance of the catalyst under the three reforming conditions studied here.

\section{Thermodynamic analysis of carbon deposition}

The equilibrium carbon deposition corresponding to each reaction was calculated at different temperatures, and the results are shown in Fig. 3.

Figure 3 shows that there is a significant thermodynamic driving force for carbon formation at temperatures below $\sim 800{ }^{\circ} \mathrm{C}$ for all three reactions, with the following trend: 


\section{Dry-reforming @750 ${ }^{\circ} \mathrm{C}$}

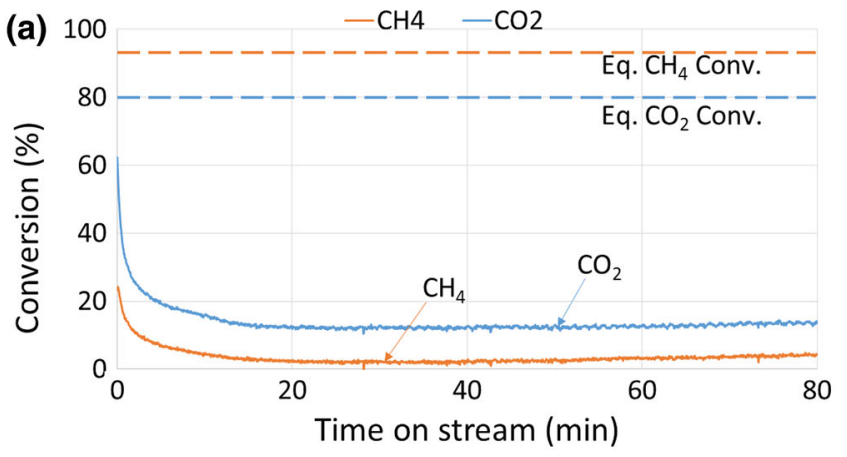

Bi-reforming @750 ㄷ

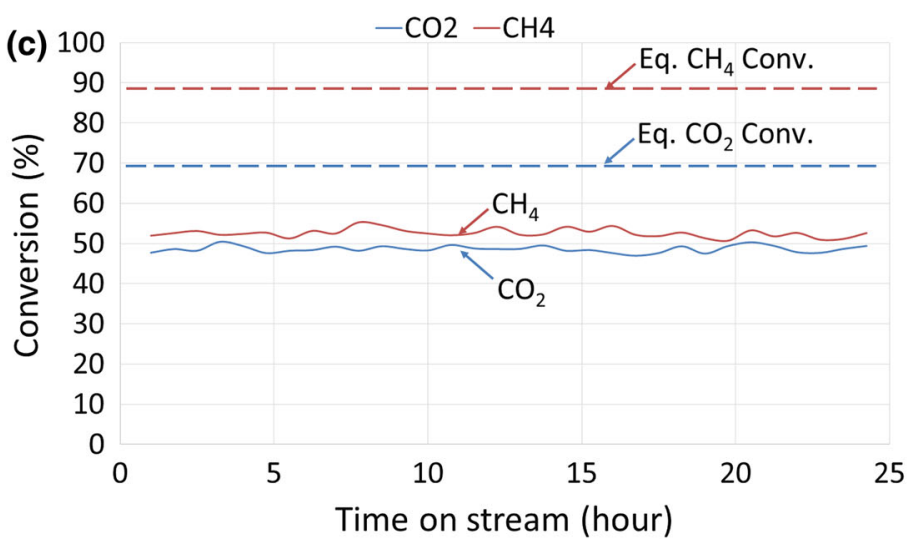

Oxy-Reforming @ $750{ }^{\circ} \mathrm{C}$

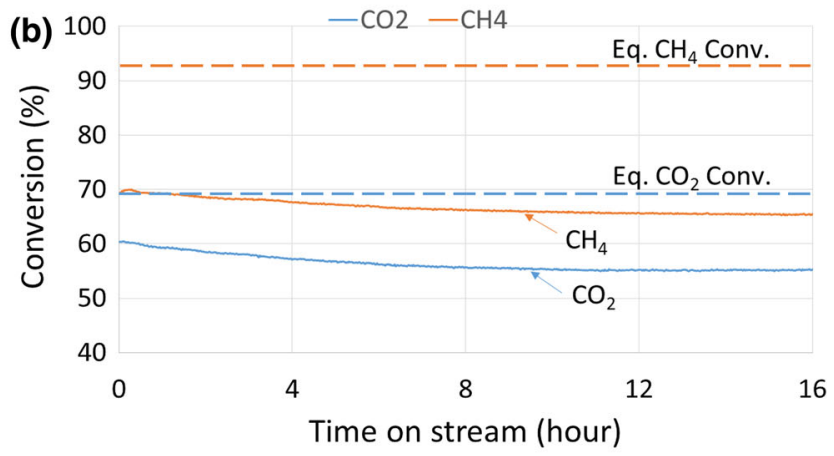

Fig. 4 Time-on-stream tests for $1 \%$ LNZ catalyst at $750{ }^{\circ} \mathrm{C}$ for a dry-reforming, b oxy-reforming, $\mathbf{c}$ bi-reforming. The feed compositions for each reaction were taken as shown in Table 1. Broken lines represent the equilibrium conversions corresponding to each conditions

Dry-reforming $>$ oxy-reforming $>$ bi-reforming

The carbon deposition is thermodynamically least favorable in the case of bi-reforming, as compared to the other two reforming conditions. However, kinetics can limit the carbon-removal reactions, and carbon formation could be significant, even at high temperatures [3].

\section{Catalyst activity with time-on-stream}

The activity of $1 \%$ LNZ catalyst with time-on-stream at $750{ }^{\circ} \mathrm{C}$ is plotted in Fig. 4 for all three reforming reactions. The inlet feed was fixed for each reaction as shown in Table 1. Note that the equilibrium conversions in Fig. $4 \mathrm{a}-\mathrm{c}$ differ for each of the three reforming reactions due to different stoichiometric feed concentrations.

Rapid deactivation of $1 \%$ LNZ catalyst is clearly seen under dry-reforming conditions. For oxy-reforming, the catalyst is much more resistant to deactivation as compared to dry-reforming. For the bi-reforming, however, the catalyst does not deactivate for at least $24 \mathrm{~h}$ time-on-stream at $750{ }^{\circ} \mathrm{C}$. As judged by the $\mathrm{CH}_{4}$ and $\mathrm{CO}_{2}$ conversions, bireforming conditions produce the most stable syngas product on this $1 \%$ LNZ catalyst.
It has been reported [26-30] that the presence of oxidizing agents, such as $\mathrm{O}_{2}$ or $\mathrm{H}_{2} \mathrm{O}$, can minimize the surface carbon deposition in methane reforming. The mechanism of carbon removal is generally thought to be due to the oxidation of the carbon precursor species [partially dehydrogenated $\mathrm{CH}_{\mathrm{x}}$ species and/or $\mathrm{C}_{(\mathrm{s})}$ ] in the presence of oxidizing agents, such as $\mathrm{O}_{2}$ or $\mathrm{H}_{2} \mathrm{O}$ [26]. For the work reported here, this is why the carbon formation is limited for the $1 \%$ LNZ catalyst in the presence of an oxidizing agent, e.g., $\mathrm{O}_{2}$ in oxy-reforming and $\mathrm{H}_{2} \mathrm{O}$ in bi-reforming.

\section{Carbon deposition studies}

The carbon deposition was studied using temperature program oxidation (TPO) for the spent catalysts from all three reactions.

Figure 5 shows three distinct TPO peaks for the spent catalyst from dry-reforming. The peak at $450{ }^{\circ} \mathrm{C}$ can be assigned due to amorphous, atomic carbon, $\mathrm{C}_{\alpha}$, which can be relatively easily gasified $[3,31,32]$. Peak at $626^{\circ} \mathrm{C}$ could be due to the polymeric carbon, $\mathrm{C}_{\beta}$, which can form as a result of rearrangement of the $\mathrm{C}_{\alpha}$ carbons and is relatively less reactive. Finally, the peak at $717^{\circ} \mathrm{C}$ can be 
Fig. 5 Temperature program oxidation results for spent catalysts from different reactions

\section{1\%LNZ TPO Results}

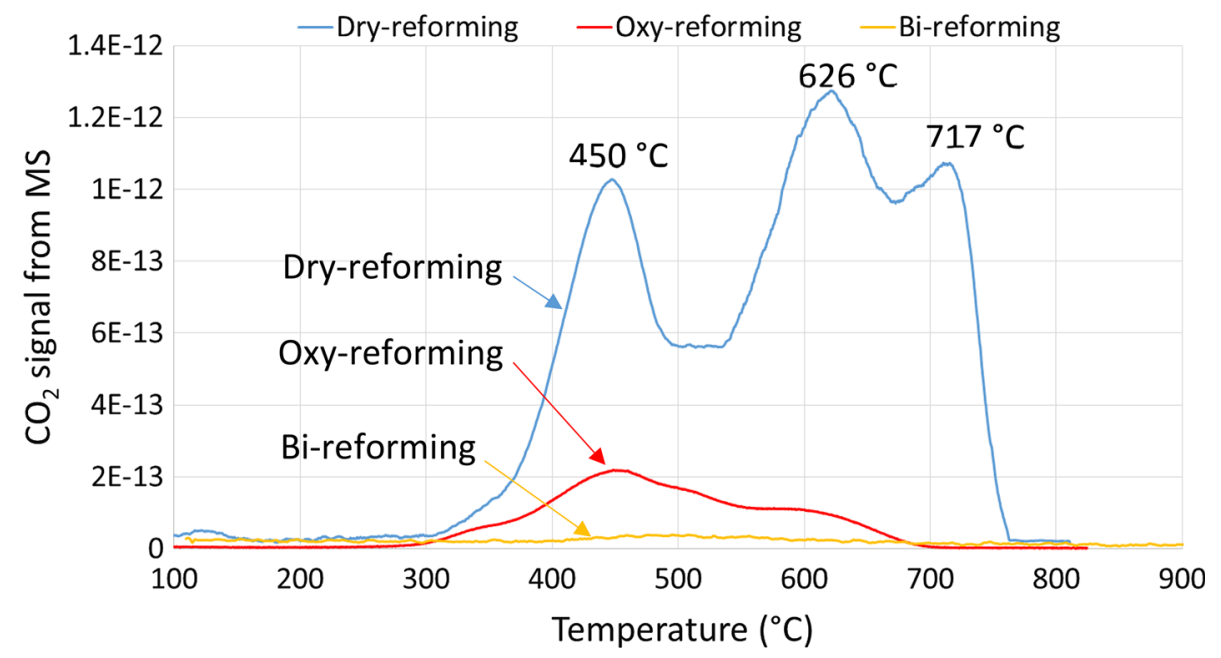

assigned due to the formation of carbon filaments or graphitic form of carbon, also known as 'whiskers' $[14,32,33]$. These whiskers are mechanically very strong and can permanently deactivate the catalyst.

For the spent catalyst from oxy-reforming, only peaks corresponding to $\mathrm{C}_{\alpha}$ and $\mathrm{C}_{\beta}$ are observed, and no graphitic carbons are present. The less reactivity, and less amount of carbon in oxy-reforming compared to dry-reforming is clearly the reason that there is far less deactivation in oxyreforming than in dry-reforming (Fig. 4a, b). For example, this is also evident from the fact that the $C_{\beta}$ peak is much smaller in area compared to that of the $\mathrm{C}_{\alpha}$ peak for the oxyreforming reaction. This is not the case with the dry-reforming reaction, where $\mathrm{C}-\mathrm{C}$ chain growth is pronounced for the carbon deposition, leading to the formation of refractory graphitic carbon. For the spent catalyst after the bi-reforming reaction, however, no significant amount of carbon is observed in the TPO, indicating that steam in the reactants appears to react more rapidly with the surface carbon than under oxy-reforming conditions.

The activity of the catalyst with time-on-stream for these reactions (Fig. 4) can be directly correlated to the amount of carbon deposited on the active sites of the catalyst. A rapid decrease in the catalytic activity under dryreforming conditions is due to excessive carbon deposition under more highly reducing conditions of dry-reforming compared to the other reforming conditions. The far less rapid decrease in activity with time-on-stream for the oxyreforming reaction (Fig. 4b) is directly related to far less amount (and far less reactive) of carbon deposited on the catalyst, as seen in Fig. 5.

Finally, the lack of any significant deactivation under bireforming conditions can be attributed to the lack of any significant carbon deposition. The carbon depositions for the spent catalysts from all three reactions are consistent and directly attributable to their deactivation. These results are also consistent with the thermodynamics of carbon deposition as shown in Fig. 3.

\section{Conclusions}

One wt $\%$ Ni-doped with $\mathrm{La}_{2} \mathrm{Zr}_{2} \mathrm{O}_{7}$ pyrochlore catalyst has been tested in three types of methane reforming reaction conditions. The pyrochlore crystalline structure is stable at these demanding conditions, as indicated by XRD. Under dryreforming and oxy-reforming conditions, carbon deposition appears to be directly and solely responsible for deactivation. Carbon deposition is far more extensive in dry-reforming than other conditions. However, no observable carbon is found under bi-reforming conditions. There is no evidence in XRD or TPR that nickel sinters or causes deactivation.

The presence of an oxidizing agent, such as $\mathrm{O}_{2}$ in the case of oxy-reforming and steam in the case of bi-reforming, significantly reduces the deactivation compared to dry-reforming. Steam in the inlet (i.e., in bi-reforming) appears to oxidize carbon or its precursors, with no measurable deactivation over a 24 -h period.

Acknowledgments We acknowledge financial support from Climate Change and Emissions Management Corporation (CCEMC), Canada. Dr. Arun Raju at UC, Riverside is gratefully acknowledged for bireforming process development. We are also grateful to Daniel Haynes at NETL, DOE for synthesis of the catalyst.

Open Access This article is distributed under the terms of the Creative Commons Attribution 4.0 International License (http:// creativecommons.org/licenses/by/4.0/), which permits unrestricted use, distribution, and reproduction in any medium, provided you give appropriate credit to the original author(s) and the source, provide a link to the Creative Commons license, and indicate if changes were made. 


\section{References}

1. Raju ASK, Park CS, Norbeck JM (2009) Synthesis gas production using steam hydrogasification and steam reforming. Fuel Process Technol 90(2):330-336

2. Gangadharan P, Kanchi KC, Lou HH (2012) Evaluation of the economic and environmental impact of combining dry reforming with steam reforming of methane. Chem Eng Res Des 90(11):1956-1968

3. Kumar N, Shojaee M, Spivey JJ (2015) Catalytic bi-reforming of methane: from greenhouse gases to syngas. Curr Opin Chem Eng 9:8-15

4. York AE, Xiao T, Green MH (2003) Brief Overview of the Partial Oxidation of Methane to Synthesis Gas. Top Catal 22(3-4):345-358

5. Kumar N, Smith ML, Spivey JJ (2012) Characterization and testing of silica-supported cobalt-palladium catalysts for conversion of syngas to oxygenates. J Catal 289:218-226

6. Kumar N, Payzant EA et al (2011) Combined in situ XRD and in situ XANES studies on the reduction behavior of a rhenium promoted cobalt catalyst. Phys Chem Chem Phys 13(32):14735-14741

7. Kumar N et al (2011) In Situ FT-IR Study on the Effect of Cobalt Precursors on CO Adsorption Behavior. J Phys Chem C 115(4):990-998

8. Spivey JJ, Egbebi A (2007) Heterogeneous catalytic synthesis of ethanol from biomass-derived syngas. Chem Soc Rev 36(9):1514-1528

9. Pakhare D, Spivey J (2014) A review of dry (CO2) reforming of methane over noble metal catalysts. Chem Soc Rev 43(22):7813-7837

10. Pakhare D, Wu H et al (2013) Characterization and activity study of the Rh-substituted pyrochlores for $\mathrm{CO} 2$ (dry) reforming of CH4. Appl Petrochem Res 3(3-4):117-129

11. Pakhare D, Haynes D et al (2012) Role of metal substitution in lanthanum zirconate pyrochlores (La2Zr2O7) for dry (CO2) reforming of methane (DRM). Appl Petrochem Res 2(1-2):27-35

12. Gaur S, Haynes DJ, Spivey JJ (2011) Rh, Ni, and Ca substituted pyrochlore catalysts for dry reforming of methane. Appl Catal A 403(1-2):142-151

13. Ramachandran CS, Balasubramanian V, Ananthapadmanabhan $P$ (2013) Thermal cycling behaviour of plasma sprayed lanthanum zirconate based coatings under concurrent infiltration by a molten glass concoction. Ceram Int 39(2):1413-1431

14. Liu C-J, Ye J et al (2011) Progresses in the Preparation of Coke Resistant Ni-based Catalyst for Steam and CO2 Reforming of Methane. Chem Cat Chem 3(3):529-541

15. Ashcroft AT, Cheetam AK et al (1992) An in situ study of pyrochlore-type catalysts for the formation of synthesis gas from methane and carbon dioxide. R Soc Chem 114:184-189 (Catalysis and Surface Characterisation)

16. Pechini PM (1967) Method of preparing lead and alkaline earth titanates and niobates and coating method using the same to form a capacitor. In: Patents U (ed). Sprague Electric Co, USA

17. Haynes DJ, Berry DA et al (2008) Catalytic partial oxidation of n-tetradecane using pyrochlores: effect of $\mathrm{Rh}$ and $\mathrm{Sr}$ substitution. Catal Today 136(3-4):206-213
18. Tietz F, Schmidt A, Zahid M (2004) Investigation of the quasiternary system LaMnO3-LaCoO3-"LaCuO3"-I: the series $\mathrm{La}(\mathrm{Mn} 0.5 \mathrm{Co} 0.5) 1-\mathrm{xCuxO}-\delta$. J Solid State Chem 177(3):745-751

19. Majid A, Tunney $\mathrm{J}$ et al (2005) Preparation of $\mathrm{SrFeO} \sim 2.85$ perovskite using a citric acid assisted Pechini-type method. J Alloys Compd 398(1-2):48-54

20. Lepe FJ, Fernández-Urbán J et al (2005) Synthesis and electrical properties of new rare-earth titanium perovskites for SOFC anode applications. J Power Sources 151:74-78

21. Kumar N, Roy A et al (2016) Bi-reforming of methane on Nibased pyrochlore catalyst. Appl Catal A 517:211-216

22. Bai CS, Soled S et al (1992) The preparation and characterization of the phases formed by the reactions of nickel and lanthanum nitrates with magnesium aluminate. J Solid State Chem 100(2):307-312

23. Rodulfo-Baechler SA, Pernía W et al (2006) Influence of lanthanum carbonate phases of $\mathrm{Ni} / \mathrm{La} 0.98 \mathrm{Sr} 0.02 \mathrm{O} \times$ catalyst over the oxidative transformation of methane. Catal Lett 112(3-4):231-237

24. Sania Maria de Lima, Assaf JM (2002) Synthesis and Characterization of $\mathrm{LaNiO} 3, \mathrm{LaNi}(1-\mathrm{x}) \mathrm{FexO} 3$ and $\mathrm{LaNi}(1-\mathrm{x}) \mathrm{CoxO} 3$ Perovskite Oxides for Catalysis Application. Mater Res 5(3):329-335

25. Mile B, Stirling D et al (1988) The location of nickel oxide and nickel in silica-supported catalysts: two forms of "NiO" and the assignment of temperature-programmed reduction profiles. J Catal 114(2):217-229

26. Choudhary VR, Mondal KC (2006) CO2 reforming of methane combined with steam reforming or partial oxidation of methane to syngas over $\mathrm{NdCoO} 3$ perovskite-type mixed metal-oxide catalyst. Appl Energy 83(9):1024-1032

27. Choudhary VR, Mondal KC, Choudhary TV (2006) Oxy-CO2 reforming of methane to syngas over $\mathrm{CoOx} / \mathrm{MgO} / \mathrm{SA}-5205$ catalyst. Fuel 85(17-18):2484-2488

28. Choudhary VR, Mondal KC, Choudhary TV (2006) Oxy-CO2 Reforming of Methane to Syngas over CoOx/CeO2/SA-5205 Catalyst. Energy Fuels 20(5):1753-1756

29. Choudhary VR, Rajput AM (1996) Simultaneous Carbon Dioxide and Steam Reforming of Methane to Syngas over NiO-CaO Catalyst. Ind Eng Chem Res 35(11):3934-3939

30. Choudhary VR, Uphade BS, Mamman AS (1998) Simultaneous steam and $\mathrm{CO} 2$ reforming of methaneto syngas over $\mathrm{NiO} / \mathrm{MgO} /$ SA-5205 in presence and absence of oxygen. Appl Catal A 168(1):33-46

31. Itkulova SS, Zakumbaeva GD et al (2014) Syngas production by bireforming of methane over Co-based alumina-supported catalysts. Catal Today 228(0):194-198

32. Trimm DL (1997) Coke formation and minimisation during steam reforming reactions. Catal Today 37(3):233-238

33. Snoeck JW, Froment GF, Fowles M (2002) Steam/CO2 Reforming of Methane. Carbon Filament Formation by the Boudouard Reaction and Gasification by $\mathrm{CO} 2$, by $\mathrm{H} 2$, and by Steam: Kinetic Study. Ind Eng Chem Res 41(17):4252-4265 